\title{
Ultrasonic Pulse Velocity in Concrete Using Direct and Indirect Transmission
}

\author{
by Ismail Ozgur Yaman, Gokhan Inci, Nazli Yesiller, and Haluk M. Aktan
}

\begin{abstract}
The relationship between velocities of ultrasonic stress waves transmitted along direct and indirect paths was investigated. Tests were conducted on plain concrete slabs of dimensions $1000 \times 1500 \mathrm{~mm}$, with a thickness of $250 \mathrm{~mm}$. Direct ultrasonic wave transmission tests were conducted between top and bottom surfaces of the slabs and indirect tests were conducted along the slab surface. A test procedure, described in BS 1881 to determine indirect wave velocities, was refined by defining the number and spacing of transducers. Comparisons were made between direct and indirect wave velocity measurements using statistical analysis. The statistical analysis revealed that direct and indirect wave velocities could be used interchangeably in evaluating the properties of the concrete. The minimum number of test points required for a reliable estimate of indirect wave velocity was studied and recommendations are provided.
\end{abstract}

Keywords' durability: pulse velocity: test: ultrasonic.

\section{INTRODUCTION}

Ultrasonic measurements are used in structural engineering to determine material properties, detect defects, and assess deterioration. Ultrasonic wave propagation characteristics that can be used for these purposes are: velocity, attenuation, frequency, and energy. In assessing material deterioration, a reference property value, such as ultrasonic pulse velocity (UPV), is determined using laboratory specimens. Field measurements are compared with the reference property value to assess the condition of the material. The ratio of field UPVS to the reference UPV indicates the level of material deterioration (Tomsett 1980; Swamy and A]Hamed 1982: Ravindrarajah 1992; Udegbunam et al. 1999).

In the laboratory, access is generally available to opposite surfaces of a test specimen, and ultrasonic tests are commonly conducted using direct transmission. Direct transmission is defined as the propagation of ultrasonic stress waves along a straight-line path between the opposite surfaces of a specimen. In the field, however, access to opposite surfaces of a component may not be readily available (for example, concrete pavements and bridge decks), and tests may need to be conducted using indirect transmission. Indirect, or surface, transmission is defined as the propagation of ultrasonic stress waves between points that are located on the same surface of the material. [n implementing procedures for deterioration assessment of structures, direct transmission measurements may be compared with indirect transmission measurements. In these comparisons, the assumption is that UPVS measured by these two methods are similar (Malhotra and Carino 1991; Tomsett 1980), and the differences in UPVS are inferred to be due to differences in material properties and conditions.

A structural assessment procedure based on a parameter described as the paste quality loss (PQL) evaluated from measured UPV is being explored. The PQL parameter and the associated procedure are proposed for durability assessment of new concrete bridge decks. The PQL parameter has a theoretical basis utilizing a relation between concrete permeability and UPV. In obtaining PQL, UPV measured on standard cylindrical specimens made from bridge deck concrete are compared with the field UPV measurements performed on bridge decks using indirect transmission. The decrease in the measured UPV on a bridge deck compared with the UPV measured on a standard specimen is proportional to PQL and indicates a loss of soundness associated with higher permeability of the bridge deck (Udegbunam et al. 1999; Yaman, Udegbunam, and Aktan 2000). In an experimental study by Udegbunam et al. (1999). UPV measurements were correlated to rapid chloride permeability test (RCPT) data. Measurements were made on standard cylinder specimens with water-cement ratios ( $w / c s$ ) between 0.35 and 0.55 using one type of coarse aggregate. The correlation showed that an increase of 1000 coulombs measured by the RCPT corresponded to a decrease in UPV of $65 \mathrm{~m} / \mathrm{s}$.

\section{RESEARCH SIGNIFICANCE}

Experimental analyses were conducted to determine direct and indirect wave velocities on two plain concrete slab specimens representing a bridge deck portion. Experimental data are presented for the comparison of UPVS measured using direct and indirect transmission. The results show that indirect surface measurements can be used to obtain a wave speed that is equal to that obtained from a through transmission test. Recommendations are made for conducting indirect UPV tests.

\section{BACKGROUND}

UPV measurement is typically performed using a pair of transducers in contact with the specimen through a coupling medium. Piezoelectric transducers are the most common types used for generating ultrasonic waves. Ultrasonic waves are generated by exciting the piezoelectric element in one transducer by an electrical voltage signal in the shape of a spike, which causes it to vibrate at its resonant frequency. These vibrations excite the material with a wide range of ultrasonic frequencies through contact and generate stress waves that are transmitted through the material to the receiving transducer. The time it takes for the ultrasonic wave to propagate to the receiving transducer is measured and defined as the time of flight. The UPV is computed from the distance between transducers and the measured time of flight.

ACI Materals Journal, V 98, No 6, November-December 2001 MS No 00-264 received November 9,2000 and reviewed under Institute publicallon policies Copynght $\bigcirc 2001$, American Concrete Insutute Al rights reserved, ncluding the making of copies unless permission is obtaned from the copyright propretors Pertment discussion will be published in the Septembet-Octobet 2002 ACl Matertat Jommal if recesved by June 1, 2002 
Ismail Oxgur Yaman is a posidoctoral research fellow in the civil engineering department at Wayme State University. Detwit, Mich. His research interests include mechancs of materials, nondestructive evaluaton of concrete structures with emphasis on ulrasont resting, and finte elemen analysis of structures.

Gokhan Inci is a PhD candidate in the cuil engineering department a Wane State

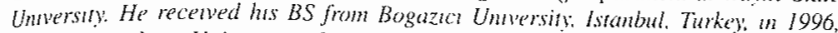
and his MS from University of New Souh Wales, Sydney. Ausmalia, in 1998. His research inte'sts include nondestructive evaluation and mumerical methods of analysis in geotechical engineerng.

Nazi Yesiller is an assisiant professor of civl engineering al Wayne State University. Her rescarch interests include geoenvironmental engmeering with an emphasis in nondestructive evaluation of geomembranes and compacted clay soils and thermal unalysis of landfill processes.

ACl member Haluk M. Aktan is a professor of civil engineering as Wayne State Unversiry. He is an assocuate member of ACl Committee 228, Nondestructive Testmg of Concrete. His research interests include nondestractive evaluaton of concrete strucures with an emphasts on stracture and infrastracture durablity.

Many studies have been conducted on direct pulse velocity determination and factors that affect it. Standards are available for measuring velocity using direct transmission (ASTM 1999a,b; RILEM 1972; BS 1997). Less information, however, is available on indirect transmission. In general, indirect transmission is used when only one face of the concrete structure is accessible, and it is often stated that indirect measurements are not reliable (ASTM 1999a; RILEM 1972; BS 1997). Moreover, indirect transmission is described as the least sensitive testing arrangement. British Standards (BS 1881) state that the indirect velocity is 5 to $20 \%$ lower than direct velocity, depending mostly on the concrete quality. Jones (1962) explained the discrepancy between the direct and indirect velocity as being due to wave dispersion. Popovics et al. (1998) verified Jones's (1962) finding by demonstrating that accurate algorithms for determining the time of flight reduce the difference between direct and indirect velocities. British Standards (BS 1881) recommends an indirect velocity measurement procedure using a relationship between transducer spacing and time of flight, obtained by repeating time-of-flight measurements with increasing distance between the transducers. Indirect measurements are not recommended in ASTM C 597 except when only one surface of a material is accessible. Furthermore, it is stated that measurements on the surface are indicative of properties of only the layers that are close to the surface. At present, ASTM standards for indirect UPV measurements do not exist.

A comparison of direct and indirect UPV measurements was presented by Qixian and Bungey (1996). Primary (P), shear $(S)$, and Rayleigh $(R)$ wave velocities were determined by surface measurements on concrete specimens with dimensions of $500^{\circ} \times 500 \times 200 \mathrm{~mm}$. Measurements were performed at six transducer spacings ranging from 50 to $300 \mathrm{~mm}$ in $50 \mathrm{~mm}$ increments, and indirect velocities were computed as recommended by British Standards (BS 1881) from the time of flight versus transducer spacing relation. Direct velocities were measured for comparison to indirect velocities but on different specimens made using the same concrete batch. It was reported that, in general, the direct waye velocities were higher than the indirect wave velocities.

Sansalone, Lin, and Street (1997) presented an application of indirect transmission on concrete. A P-wave velocity measurement technique was developed for impact-echo testing. The technique was proposed for determining the thickness of concrete elements and to locate defects in concrete. Two transducers with pointed tips were placed on the surface of a concrete slab, and an impact was generated at a point along a line drawn between the axes of the two transducers. The wave velocity was calculated as the ratio of the distance between the transducers to the time of flight between the transducers. Recommendations were made for transducer spacing in determining the wave velocity.

Indirect UPV measurements were also compared with direct measurements by Popovics et al. (1998) using a similar procedure used by Sansalone, Lin, and Streett (1997). The UPV measurements were performed using a pair of accelerometers coupled directly to the specimen surface and the stress waves were generated by an impactor. The equality of indirect to direct UPV was verified for a homogeneous material. The surface and through thickness properties and the UPVs diverged in concrete specimens with a moisture gradient.

Benedetti (1998) investigated the depth of fire damage to concrete columns using principles similar to geophysical prospecting. An analytical solution was presented for the wave path from a transmitting transducer to a receiving transducer placed on the surface of the fire-damaged concrete component. Assuming layers with finite thickness and constant velocity, Benedetti (1998) showed that a simplified analysis technique similar to that used in geophysical testing (Richart, Hall, and Woods 1970) could be used, however, a more realistic analysis assuming linear variation of UPV through the damaged zone showed that the fastest wave path between the transmitting and receiving transducers was a cycloid. In addition, Benedetti (1998) made recommendations for optimum transmitting and receiving transducer spacing for achieving maximum measurement resolution.

In summary, procedures for determining direct UPV are well-established, and the measurements are used to assess various concrete properties. Several studies employing indirect UPV measurements on concrete are reported in the literature; however, agreement has not been reached on the relation between direct and indirect UPV and on the methods of indirect UPV measurement.

\section{EXPERIMENTAL PROGRAM}

The experimental study consisted of the measurement and comparison of UPVs obtained using direct and indirect transducer arrangements on the same specimens. Measurements were performed on two plain concrete slab specimens with dimensions of $1500 \mathrm{~mm}$ width, $1000 \mathrm{~mm}$ length, and $250 \mathrm{~mm}$ thickness. The primary goal of the study was the development of a reliable and more refined procedure for indirect UPV measurements.

Direct and indirect UPV measurements were made simultaneously on the slab specimens at an age of 28 days. A membrane-forming curing compound was applied to the specimen surface as required by the Michigan Department of Transportation (MDOT) bridge deck specifications. It is assumed that, at an age of 28 days, the moisture profile along the specimen depth will be approximately constant.

\section{Equipment}

The UPV measurement equipment consisted of three components: 1) two transducers; 2) a pulser-receiver unit; and 3) the data acquisition system. A pair of $50 \mathrm{kHz}$ narrowband transducers with a diameter of $44.5 \mathrm{~mm}$ was used for measurements, one transducer for transmitting the pulse, and the other for capturing the ultrasonic waves. The pulser-receiver unit excited the transmitting transducer and conditioned the 

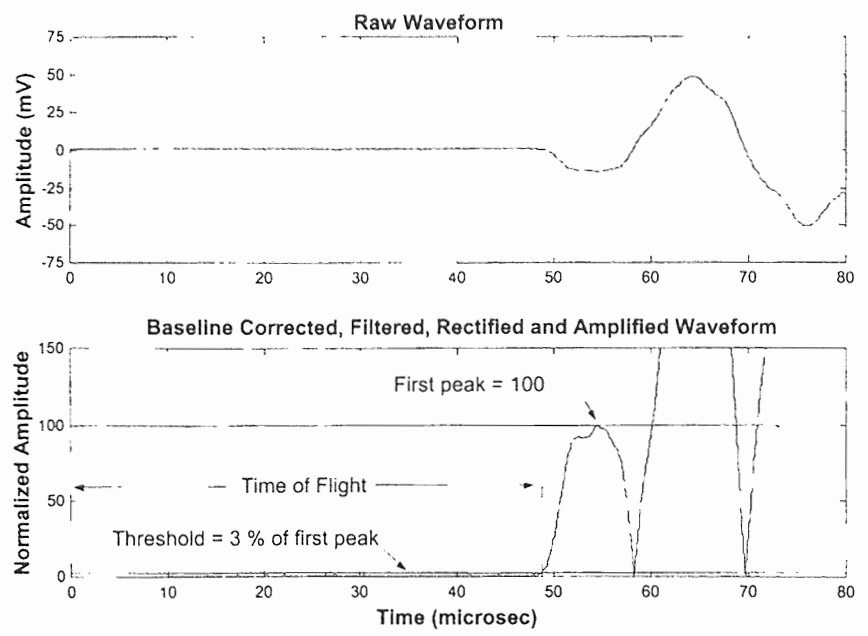

Fig. 1-Procedure for determination of wave time of flight.

receiving transducer signal. The conditioned receiver signal was acquired by a high-speed ( $100 \mathrm{MHz}$ sampling rate) ana$\log$ to digital (A/D) data acquisition board. The $10 \mathrm{MHz}$ bandwidth pulser-receiver had an adjustable repetition rate between $20 \mathrm{~Hz}$ to $2 \mathrm{kHz}$, with a $1 \mathrm{~V}$ output for synchronous triggering of the A/D board during data acquisition. A computer algorithm was developed based on a fixed threshold level for determination of the time of flight using the digitally acquired waveforms. The procedures, test setup, and equipment were described in detail by Yaman, Udegbunam, and Aktan (2000).

\section{Laboratory slab specimens}

Tests were conducted on two plain concrete slab specimens ( $\mathrm{PC} 1$ and $\mathrm{PC} 2$ ) representing a bridge deck portion. The concrete used was a mixture commonly specified by MDOT for bridge deck construction and was supplied by a MDOT certified ready-mix contractor. The specified $w / c$ of the mixture was 0.45 with $6 \%$ entrained air content. The mixture contained Type I cement and limestone aggregates of $1.13 \%$ absorption with a maximum coarse aggregate size of $25 \mathrm{~mm}$. At the time of concrete placement, slump was measured as $100 \mathrm{~mm}$, density as $2250 \mathrm{~kg} / \mathrm{m}^{3}$, and entrained air as $5.7 \%$. The Type A curing compound was applied to the surface of the slab $2 \mathrm{~h}$ after casting. The specimens were moist-cured for 7 days by covering with saturated burlap with a bleed hose and wrapping with plastic sheeting. Beyond the eighth day, the specimens were kept in laboratory air.

The concrete mechanical properties were determined by tests performed on twenty $150 \mathrm{~mm}$ diameter and sixteen $100 \mathrm{~mm}$ diameter standard cylinders that were prepared from the same batch of concrete. The standard specimens were moistcured for 28 days. Compressive strength, static modulus of elasticity, Poisson's ratio, density, and direct UPV tests were conducted on the standard specimens at 7, 14, and 28 days. The compressive strength (ASTM C 39), modulus of elasticity, and Poisson's ratio tests (ASTM C 469) were conducted on $150 \mathrm{~mm}$ diameter standard cylinders. The specific gravity (ASTM C 642) and direct UPV tests (ASTM C 597) were conducted on $100 \mathrm{~mm}$ diameter cylinders. The average results for the 28-day tests were $41 \mathrm{MPa}$ for strength, $36 \mathrm{GPa}$ for the modulus of elasticity, 0.26 for the Poisson's ratio, and 2.312 for the specific gravity. The 28-day average direct UPV measured on the standard cylindrical specimens was $4509 \mathrm{~m} / \mathrm{s}$, with a standard deviation of $60 \mathrm{~m} / \mathrm{s}$.

\section{Ultrasonic pulse velocity (UPV) measurements}

Before performing the UPV measurements, error analysis was conducted to determine the systematic error that results from equipment calibration and measurement errors associ. ated with determination of path length and time of flight. The systematic equipment error was determined to be very small $(0.07 \mu \mathrm{s})$ compared with the measured time of flight; hence, it was ignored in the UPV calculations. The measurement error in determining the time of flight due to digital data was $0.2 \%$ for the signals digitized at a $50 \mathrm{MHz}$ sampling rate.

The UPV measurements were performed with the digital scope board synchronized with the pulser-receiver unit, so that data collection started at the time of pulse application. Measurement of time of flight was affected by the electrical noise superimposed with the waveform. Therefore, to minmize random errors associated with identifying the arrival time, wave averaging of 64 waveforms was performed. The first step in identifying the time of flight from the waveform was establishing the baseline. Afterwards, the waveform was further smoothened by using a 10-point moving average filter. The waveform was then rectified and amplified such that the peak amplitude of the first cycle of the waveforms obtained from all the measurements were equal. The time of flight was determined as the time when the amplitude of the first point of the signal reached a fixed preset threshold of $3 \%$ of first cycle peak amplitude (Yaman, Udegbunam, and Aktan 2000). The time-of-flight algorithm is described graphically in Fig. 1. This procedure eliminated the overestimation of the time of flight for greater transducer spacings since the amplitude of the first cycle peak decreases due to dispersion of the waves. Similar procedures for the determination of the time of flight are also described in standards (RILEM 1972; ASTM 1999b). A procedure was developed in the MAT. $\mathrm{LAB}^{\circledR}$ environment to process the waveforms obtained during the measurements for both direct and indirect UPV measurements.

\section{Direct UPV measurements}

Direct velocity measurements were taken at 15 locations in each slab specimen. The direct path length for these measurements was through the slab thickness of $250 \mathrm{~mm}$. The accurate thicknesses at the measurement locations were determined using a coordinate measurement machine (CMM) with a resolution of $\pm 10 \mu \mathrm{m}$. Direct UPV was calculated as the ratio of the path length to the time of flight.

\section{Indirect UPV measurements}

A total of 54 indirect measurements were made on each concrete slab. Indirect measurements were conducted using a coordinate system drawn on the slab surface, which is shown in Fig. 2. The coordinate system consisted of a primary grid at $250 \mathrm{~mm}$ spacing and a secondary grid within the primary grid at $50 \mathrm{~mm}$ spacing. The primary gridlines were labeled along the width of the specimens as axes $\mathrm{A}, \mathrm{B}$, and $\mathrm{C}$, and along the length of the specimens as axes 10, 20,30,40, and 50 . The secondary grid was drawn inside the area bounded by axes A, C, 20, and 40. Labels of secondary grid along the specimen length were $1,2,3$, and 4 and along the specimen width were $\mathrm{j}, \mathrm{k}, \mathrm{l}, \mathrm{m}, \mathrm{n}, \mathrm{p}, \mathrm{r}$, and $\mathrm{q}$.

Indirect measurements were made along axes $\mathrm{A}, \mathrm{B}$, and $\mathrm{C}$. Transducers were placed at the grid nodes. After each measurement, the receiving transducer was moved away from the transmitting transducer starting from a center-to-center separation of 100 to $500 \mathrm{~mm}$ at approximately $50 \mathrm{~mm}$ increments. 
Table 1-Direct UPV measurements through slab thickness

\begin{tabular}{c|c|c}
\cline { 2 - 3 } \multirow{2}{*}{ Measuremenc location } & \multicolumn{2}{|c}{ Direct UPV. m/s } \\
\cline { 2 - 3 } & $\mathrm{PC1}$ & $\mathrm{PC2}$ \\
\hline A 10 & 4383 & 4491 \\
\hline A20 & 4507 & 4544 \\
\hline A30 & 4330 & 4449 \\
\hline A40 & 4504 & 4481 \\
\hline A50 & 4443 & 4562 \\
\hline B10 & 4387 & 4466 \\
\hline B20 & 4519 & 4539 \\
\hline B30 & 4506 & 4417 \\
\hline B40 & 4562 & 4535 \\
\hline B50 & 4571 & 4477 \\
\hline C10 & 4360 & 4504 \\
\hline C20 & 4539 & 4582 \\
\hline C30 & 4469 & 4418 \\
\hline C40 & 4530 & 4507 \\
\hline C.50 & 4507 & 1497 \\
\hline Average & 4475 & 1498 \\
\hline COV.\% & 1.70 & 1.09 \\
\hline
\end{tabular}

To assure that the spacing between the transducers remained constant, premeasured spacer blocks were used.

Indirect UPV determination was more elaborate than the direct UPV due to the uncertainty in wave path length. One reason for this uncertainty is the nonuniform and indeterminate surface deformation of the transducer piezoelectric crystal surface (Krautkrämer and Krautkrämer 1990). For that reason, the calculated indirect UPV could differ depending on the assumed point of excitation and the point of recep tion. This can vary between the outer rim and the inner rim of each transducer. In Fig. 3(a), the indirect LPVs were calculated at the ratio of various path lengths to the time of flight of the waves between two transducers, which will be refurred to as Method 1. In Method 1, there are three potential path length definitions as shown in Fig. 3(a), which are the center-to-center distance $L_{C-C}$, the inner rim-to-inner rim cistance $L_{I R-I R}$, and the outer rim-to-outer rim distance $I$.OR-OR. The differences in UPV from using different path length definitions can be seen in Fig 3(a). As the distance between the transmitting and receiving transducers increases, the differences in calculated UPV decrease and the UPVs converge to a constant value.

The UPV calculation using an alternative procedure (Method 2) is shown in Fig. 3(b). In this procedure, time of flight is plotted against multiple transducer spacings by rearranging the measurement data described in Fig. 3(a). The inverse of the slope from linear regression of the time of flight and transducer spacing provided the indirect UPV. UPV oblained using Method 2 was not affected by the transducer diameter because the definition of the distance between the transmitting and receiving transducers only affects the offset of the regression relation. The indirect LIPV was computed from the regression relation between nine transit time measurements at nunc receiver lncations obtained for increasing distances from the transmitting transducer. It should be noted that the L'PV computed using this procedure represents the smeared value over the largest separation, which was $495 \mathrm{~mm}$ for the measurement shown in Fig. 3(b). Similar procedures to Method 2 are described in British Standards (BS 1997) and RII.LAM recommendatuns (1972).

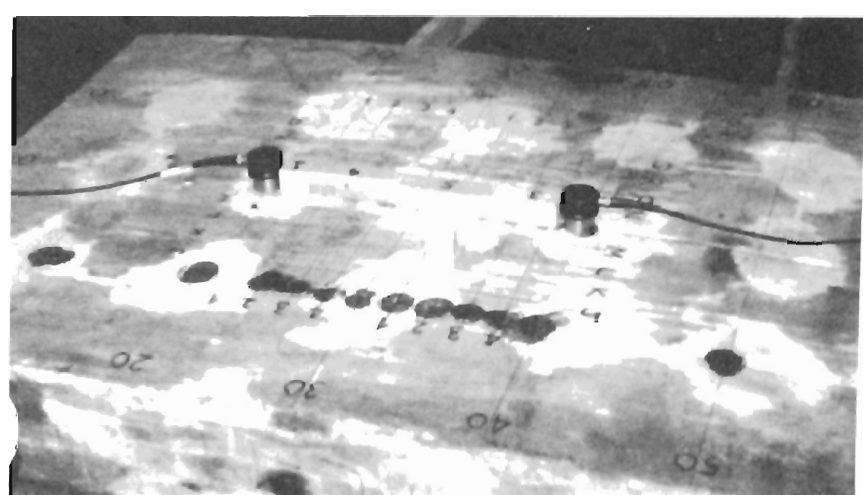

Fig. 2--Indirect UPV test grid on concrete slab surface (PCl).

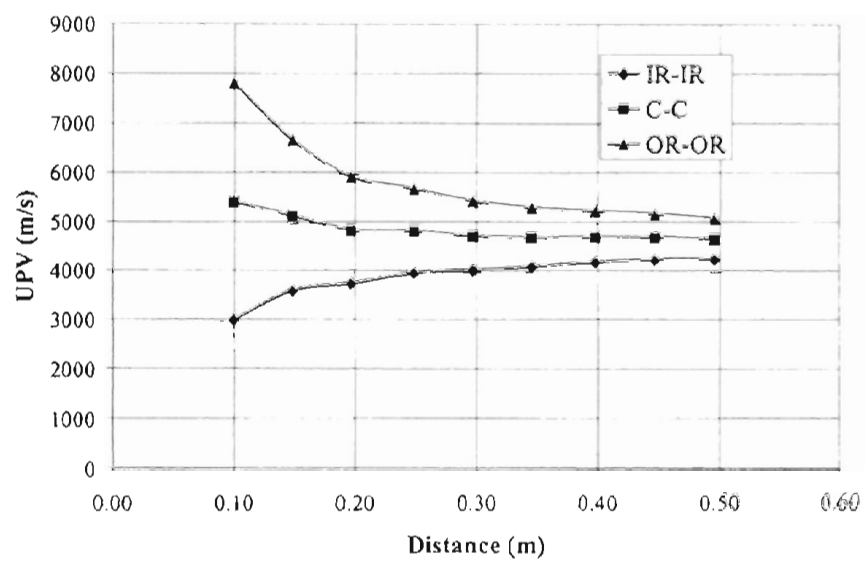

(a) Single measurement

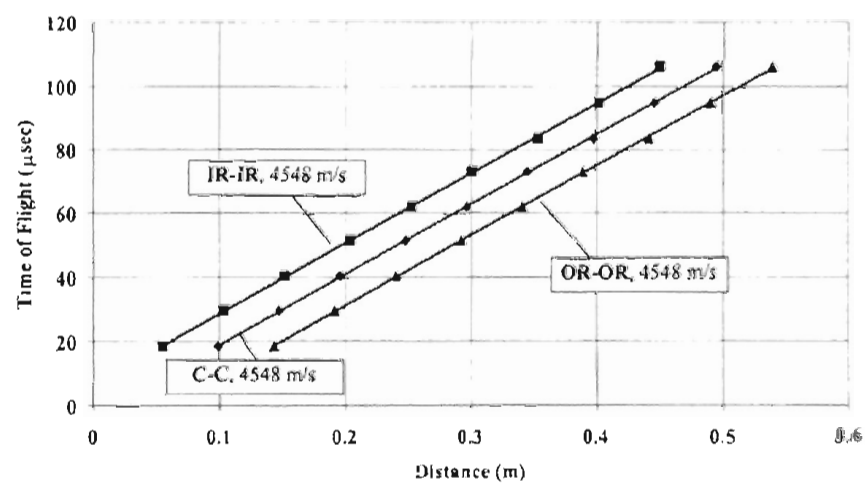

(b) Multi-measurement

Fig. 3-Methods for determining indirect UPV.

\section{EXPERIMENTAL RESULTS AND STATISTICAL ANALYSIS}

\section{Experimental results}

The testing program had two objectives. The first objective was to compare direct and indirect velocities and develop a correction fiactor, if needed. The second objective was to develop an indirect UPV measurement procedure for concrete surfaces by establishing the number of transducer locations and spacing.

Direct UPVs obtained through the thickness of the slab specimens are presented in Table 1, which represents the average of four measurements at each location. The variability of these meisurements, as described by the coefficient of variation (COV) shown in Table 1 , are $1.70 \%$ for $\mathrm{PCl}$ and $1.09 \%$ for $\mathrm{PC} 2$. 
Table 2-Indirect UPV measurements on slab surface*

\begin{tabular}{c|c|c}
\hline \multirow{2}{*}{ Pulser transducer location } & \multicolumn{2}{|c}{ Indirect UPV, $\mathrm{m} / \mathrm{s}$} \\
\cline { 2 - 3 } & $\mathrm{PCl}$ & $\mathrm{PC2}$ \\
\hline A20 & 4604 & 4494 \\
\hline A40 & 4535 & 4504 \\
\hline B20 & 4480 & 4442 \\
\hline B40 & 4486 & 4563 \\
\hline C20 & 4548 & 4584 \\
\hline C40 & 4526 & 4531 \\
\hline Average & 4530 & 4520 \\
\hline COV, \% & 1.01 & 1.13 \\
\hline
\end{tabular}

"Using measurements of nine transducers.

Table 3(a)-Second-moment statistics and goodness-of-fit test for PC1 and PC2

\begin{tabular}{c|c|c|c|c|c|c|c}
\hline \multirow{2}{*}{$\begin{array}{c}\text { Transducer } \\
\text { configuration }\end{array}$} & \multicolumn{3}{|c|}{ Statistics } & \multicolumn{2}{c}{ Goodness-of-fit test } \\
\cline { 2 - 8 } & Specimen & $\begin{array}{c}\text { Sample } \\
\text { size }\end{array}$ & $\begin{array}{c}\text { Mean, } \\
\mathrm{m} / \mathrm{s}\end{array}$ & $\begin{array}{c}\text { Standard } \\
\text { deviation, } \\
\mathrm{m} / \mathrm{s}\end{array}$ & $D_{\max }$ & $D_{5 \%} \%$ & $\begin{array}{c}\text { Probability } \\
\text { distribution }\end{array}$ \\
\hline \multirow{2}{*}{ Direct } & $\mathrm{PC} 1$ & 15 & 4475 & 76 & 0.251 & 0.34 & Normal \\
\cline { 2 - 9 } & $\mathrm{PC} 2$ & 15 & 4498 & 49 & 0.111 & 0.34 & Normal \\
\hline \multirow{2}{*}{ Indirect } & $\mathrm{PC} 1$ & 6 & 4530 & 46 & 0.178 & 0.53 & Normal \\
\cline { 2 - 8 } & $\mathrm{PC} 2$ & 6 & 4520 & 51 & 0.142 & 0.53 & Normal \\
\hline
\end{tabular}

Table $3(b)-S i m i l a r i t y$ test for direct UPV of PC1 and $\mathrm{PC} 2$

\begin{tabular}{c|c|c|c}
\hline H0: $\mu_{d 1}=\mu_{d 2}$ & $s_{p}$ & $\left|t_{0}\right|$ & $\left|t_{\alpha / 2, n 1+n 2-2}\right|$ \\
\hline HA. $\mu_{d 1} \neq \mu_{d 2}$ & 64 & 1.00 & 2.05 \\
\hline
\end{tabular}

Table 3(c)-Similarity test for indirect UPV of PC1 and $\mathrm{PC} 2$

\begin{tabular}{c|c|c|c}
\hline H0: $\mu_{i 1}=\mu_{i 2}$ & $s_{p}$ & $\left|t_{0}\right|$ & $\left|t_{\alpha / 2, n 1+n 2-2}\right|$ \\
\hline HA. $\mu_{i 1} \neq \mu_{i 2}$ & 48 & 0.37 & 2.23 \\
\hline
\end{tabular}

Method 1 (Fig. 3(a)) show differences in indirect UPV as high as $40 \%$, which renders the method not useful and will not be discussed any further. Indirect UPVs obtained using Method 2 with nine transducer measurements were compared with the direct UPV (Table 2). To determine the repeatability of the indirect UPV measurements, the tests were conducted twice along the same path, but by reversing the transmitting and receiving transducer locations. For example, for the measurements along axis $\mathrm{A}$, the transmitting transducer was placed at grid point A20. In Table 2, A20 is described as the pulser location and the indirect UPV for Specimen PC1 was obtained as $4604 \mathrm{~m} / \mathrm{s}$ when the receiving transducer was placed at grid points A2I through A40. The measurement is reversed by placing the transmitting transducer at grid point $\mathrm{A} 40$, also shown in Table 2 as the pulser location, and moving the receiving transducer between grid points A34 through A20, which resulted in an indirect UPV of $4535 \mathrm{~m} / \mathrm{s}$. The mean values for the indirect UPV for the two slab Specimens $\mathrm{PC} 1$ and $\mathrm{PC} 2$ were computed as 4530 and $4520 \mathrm{~m} / \mathrm{s}$, with COVs of 1.01 and $1.13 \%$, respectively, as shown in Table 2 .

\section{Statistical analysis}

Statistical analysis was conducted on the direct and indirect UPV measurements to evaluate the specimen similarity of
Table 4(a)-Second-moment statistics and goodness-of-fit test for direct and indirect UPV

\begin{tabular}{|c|c|c|c|c|c|c|}
\hline \multirow[b]{2}{*}{$\begin{array}{l}\text { Transducer } \\
\text { configuration }\end{array}$} & \multicolumn{3}{|c|}{ Statistics } & \multicolumn{3}{|c|}{ Goodness-of-fil test } \\
\hline & $\begin{array}{c}\text { Sample } \\
\text { size }\end{array}$ & $\begin{array}{c}\text { Mean, } \\
\mathrm{m} / \mathrm{s}\end{array}$ & $\begin{array}{c}\text { Standard } \\
\text { deviation, } \\
\mathrm{m} / \mathrm{s}\end{array}$ & $\mathrm{D}_{\max }$ & $D_{5 \%}$ & $\begin{array}{l}\text { Probability } \\
\text { distribution }\end{array}$ \\
\hline Direct & 30 & 4486 & 64 & 0.143 & 0.24 & Normal \\
\hline Indirect & 12 & 4525 & 46 & 0.098 & 0.38 & Normal \\
\hline
\end{tabular}

Table 4(b)-Similarity test for direct and indirect UPV

\begin{tabular}{c|c|c|c}
\hline Ho: $\mu_{d l}=\mu_{i}$ & $s_{p}$ & $\left|t_{0}\right|$ & $\mid t_{0 / 2, n 1+n 2-2 \mid}$ \\
\hline HA. $\mu_{d} \neq \mu_{d}$ & 60 & 1.89 & 2.02 \\
\hline
\end{tabular}

$\mathrm{PC} 1$ and $\mathrm{PC} 2$ and to evaluate the similarity between the direct and indirect UPV.

Similarity of slab specimens-The similarity tests were conducted using second-moment statistics, and the sample size, mean, and standard deviation of direct and indirect UPV of slab Specimens PC1 and PC2 was used as shown in Table 3(a). To verify the normal distribution of the UPV measurements, the Kolmogorov-Smirnov goodness-of-fit test was applied (Ang and Tang 1975). In this test (as shown in Fig. 4), an empirical stepwise cumulative frequency distr.bution function was assumed, and the cumulative norma] distribution function was plotted for each one of the varlables presented in Table 3(a). The observed D-statistic $D_{\max }$ was less than the critical value corresponding to the commonly used 5\% level of significance (Table 3(a)). Therefore, the null hypothesis, that the data have a normal distribution, cannot be rejected at the $5 \%$ level of significance. The inference is that the direct and indirect UPV S of PC1 and PC2 can be represented as normally distributed variables with therr respective means and standard deviations.

The similarity of the UPVs for PC1 and PC2 was checked using $\mathrm{t}$-statistics. The results presented in Table $3(\mathrm{~b})$ for direct UPV and in Table 3(c) for indirect UPV show that the null hypotheses cannot be rejected. The null hypothesis ( $\mathrm{H} 0$ ) states that the means for two slabs are equal, and the alternate hypothesis (HA) states they are not equal. Consequently, a two-tailed t-test was conducted, for the comparison of direct and indirect UPV in the two slabs. A pooled estimate $s_{p}$ of the standard deviation for direct $(64 \mathrm{~m} / \mathrm{s})$ and indirect UPV $(48 \mathrm{~m} / \mathrm{s})$ was used in the $\mathrm{t}$-test as shown in Table $3(\mathrm{~b})$ and (c). In each case, the calculated t-statistic $\left|t_{0}\right|$ is less than the critical value $\left|t_{\alpha / 2, n 1+n 2-2}\right|$ at the $5 \%$ level of significance. Consequently, the direct UPV of PC1 and PC2 and the indirect UPV of PC1 and PC2 are statistically similar. Therefore, results for two slabs can be pooled to obtain an average direct UPV of $4486 \mathrm{~m} / \mathrm{s}$ and an indirect UPV of $4525 \mathrm{~m} / \mathrm{s}$.

Similarity of direct and indirect UPV-The sample size, mean, and standard deviation for direct and indirect UPV for both slab specimens are presented in Table 4(a). The Kolmogorov-Smirnov goodness-of-fit test was used again to determine if the combined UPV measurements were normally distributed. The cumulative normal distribution functions are plotted for direct and indirect UPV in Fig. 4(e) and (f).

The results of the Kolmogorov-Smirnov test that are presented in Table 4(a) show that $D_{\max }$ is less than the critical value corresponding to the $5 \%$ level of significance. Therefore, the null hypothesis, that the data have a normal distribution, cannot be rejected at the $5 \%$ level of significance, and the 


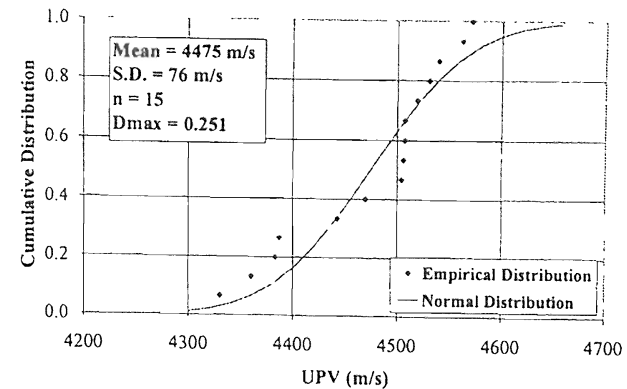

(a) Direct UPV of PCl

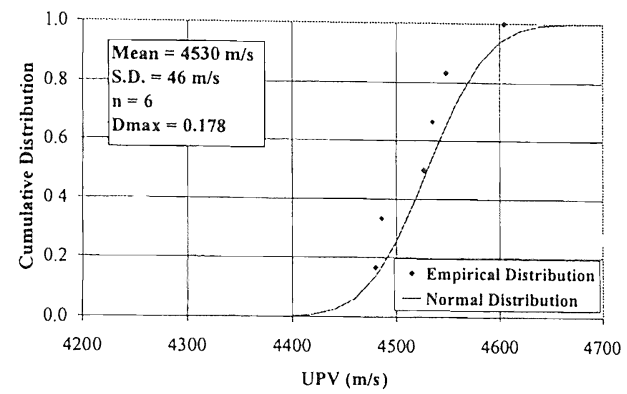

(c) Indirect UPV of PC1

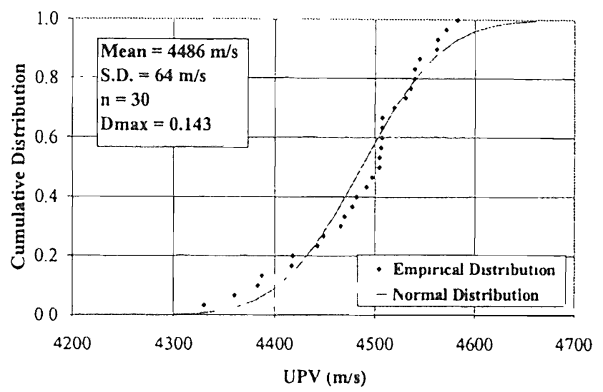

(e) Direct UPV of Combıned

$\mathrm{PCl}$ and $\mathrm{PC} 2$

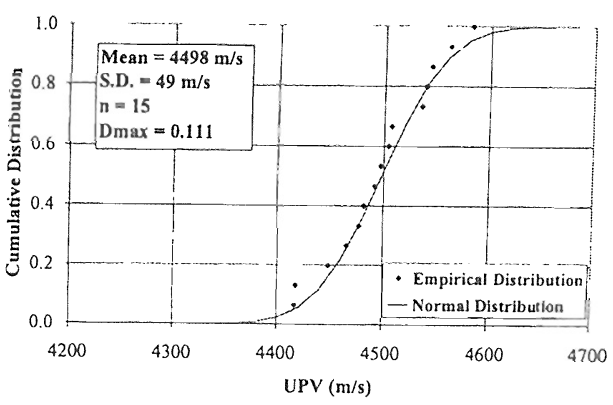

(b) Direct UPV of PC2

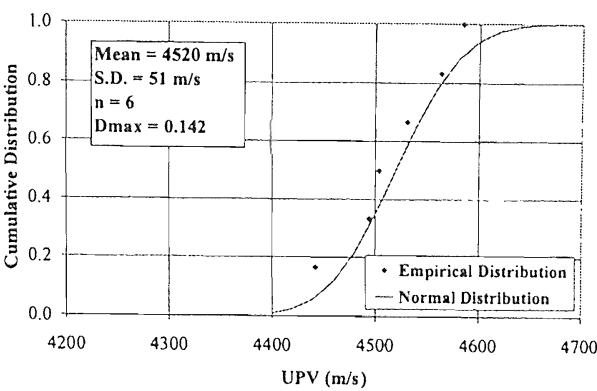

(d) Indirect UPV of PC2

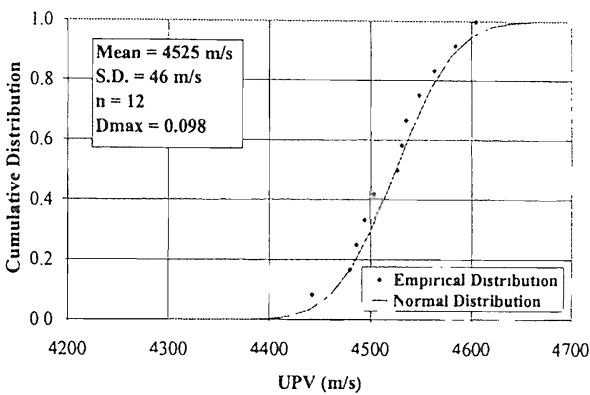

(f) Indirect UPV of Combined

$\mathrm{PC} 1$ and $\mathrm{PC} 2$

Fig. 4-Cumulative normal distribution functions of direct and indirect UPV measurements.

direct and indirect UPV of $\mathrm{PC} 1$ and $\mathrm{PC} 2$ presented in Table 4(a) can be represented as normally distributed variables with their respective means and standard deviations.

The results of the t-test for determining the similarity of direct and indirect UPV are presented in Table 4(b). As shown in the table, the null hypothesis ( $\mathrm{H} 0)$ states that both means are equal, and the alternate hypothesis (HA) states that they are not equal. To perform a two-tailed t-test, a pooled estimate of the standard deviation was computed as shown in Table 4(b). Also shown in Table 4(b), the calculated $\left|t_{0}\right|$ of 1.89 is less than the critical value of 2.02 . Thus, the null hypothesis cannot be rejected at the $5 \%$ level of significance, and therefore, the direct and indirect UPVs are statistically similar.

\section{Indirect UPV measurement procedure}

The indirect UPV used in the analysis so far was calculated from nine transducer spacings. The measurements were further analyzed to determine the least number of points that can be used to calculate the indirect UPV with an acceptable variability. This was important to increase the measurement speed when multiple receiving transducers are to be used along with one transmitting transducer.

In performing the indirect UPV measurements, the closest location of the receiving transducer to the transmitting transducer was $100 \mathrm{~mm}$. Since the wavelength of the ultrasonic wave at $50 \mathrm{kHz}$ is approximately $90 \mathrm{~mm}$, the time of flight measured at the receiver locations too close to the transmirting transducer may be influenced by the nonuniformity of coarse aggregate distribution (BS 1997). To assess the uncertainty of the measurement from the nearest location of the receiving transducer, the mean and COV of the time of flight measured at equal distances are reviewed for the transducer arrangements presented in Table 5. In Table 5, the first column is the center-to-center transducer spacing, and the following columns are the time-of-flight measurements corresponding to the transducer spacings. Also shown in Table 5 is the COV of the time-of-flight measurements at equal spacings. The COVs for transducer separations below twice the wavelength are in excess of $2 \%$, whereas the time-of-flight COV for transducer separations greater that twice the wavelength are all less than $1.2 \%$. The concrete composition. especially 
Table 5-Measured time of flight at various transducer spacings for indirect UPV measurement

\begin{tabular}{|c|c|c|c|c|c|c|c|c|c|c|c|c|c|}
\hline \multirow{4}{*}{$\begin{array}{c}\text { Transducer } \\
\text { separation, mm }\end{array}$} & \multicolumn{6}{|c|}{$\mathrm{PCl}$} & \multicolumn{6}{|c|}{$\mathrm{PC} 2$} & \multirow[b]{4}{*}{$\mathrm{COV}, \%$} \\
\hline & \multicolumn{12}{|c|}{ Pulser transducer location } & \\
\hline & $\mathrm{A} 20$ & B20 & $\mathrm{C} 20$ & $\mathrm{~A} 40$ & B40 & $\mathrm{C} 40$ & $\mathrm{~A} 20$ & $\mathrm{~B} 20$ & $\mathrm{C} 20$ & $\mathrm{~A} 40$ & $\mathrm{~B} 40$ & $\mathrm{C} 40$ & \\
\hline & \multicolumn{12}{|c|}{ Time of flight, $\mu \mathrm{sec}$} & \\
\hline 100 & 19.28 & 17.48 & 18.82 & 18.90 & 18.18 & $*$ & 18.42 & 17.52 & 18.46 & 18.52 & 18.32 & 18.30 & 2.93 \\
\hline 148 & 28.90 & 27.60 & 29.96 & $29 . \overline{78}$ & 27.48 & 29.04 & 28.98 & 28.10 & 29.06 & 29.10 & 28.76 & 29.22 & 2.65 \\
\hline 197 & 40.82 & 40.24 & 40.70 & 41.16 & 40.62 & 41.12 & 40.12 & 40.04 & 40.84 & 4110 & 40.12 & 39.70 & 1.21 \\
\hline 249 & 52.48 & 51.56 & 5172 & $51 . \overline{94}$ & 51.58 & 51.44 & 51.32 & 51.34 & 51.52 & 50.94 & 50.86 & 5110 & 0.86 \\
\hline 297 & 63.76 & 62.70 & 62.32 & 65.06 & 62.74 & 63.32 & 61.84 & 61.34 & 62.36 & 63.84 & 6170 & 62.46 & 1.68 \\
\hline 346 & 73.22 & 73.14 & 73.48 & 74.10 & 72.94 & 74.00 & 72.20 & 73.52 & 73.38 & 74.06 & 73.46 & 74.26 & 0.79 \\
\hline 398 & 84.34 & 83.36 & 83.86 & 83.38 & 85.22 & 85.56 & 84.58 & 83.98 & 83.36 & 84.68 & 85.38 & 85.02 & 0.96 \\
\hline 447 & 95.12 & 95.04 & 95.20 & 96.02 & 94.60 & 93.80 & 95.70 & 96.10 & 93.48 & 95.58 & 92.90 & 94.22 & 1.09 \\
\hline 495 & 104.26 & 106.08 & 106.56 & 106.58 & 106.08 & 106.94 & 106.58 & 106.58 & 105.78 & 106.34 & 104.96 & 105.36 & 0.75 \\
\hline
\end{tabular}

*Missing data point.

Table 6-Indirect UPV measured using different number of measurement points

\begin{tabular}{|c|c|c|c|c|c|c|c|c|c|c|c|c|c|c|}
\hline \multirow{4}{*}{$\begin{array}{c}\text { Number of } \\
\text { measurement points }\end{array}$} & \multicolumn{6}{|c|}{$\mathrm{PCl}$} & \multicolumn{6}{|c|}{$\mathrm{PC} 2$} & \multirow[b]{4}{*}{ Mean, $\mathrm{m} / \mathrm{s}$} & \multirow[b]{4}{*}{ COV, $\%$} \\
\hline & \multicolumn{12}{|c|}{ Pulser transducer location } & & \\
\hline & $\mathrm{A} 20$ & $\mathrm{~B} 20$ & $\mathrm{C} 20$ & A40 & $\mathrm{B} 40$ & $\mathrm{C} 40$ & A20 & $\mathrm{B} 20$ & $\mathrm{C} 20$ & $\mathrm{~A} 40$ & $\mathrm{~B} 40$ & $\mathrm{C} 40$ & & \\
\hline & \multicolumn{12}{|c|}{ Indirect UPV, $\mathrm{m} / \mathrm{s}$} & & \\
\hline 2 & 4466 & 4600 & 4725 & 4830 & 4751 & 5046 & 4649 & 4608 & 4875 & 5292 & 4848 & 4568 & 4771 & 4.8 \\
\hline 3 & 4385 & 4479 & 4653 & 4190 & 4547 & 4520 & 4631 & 4720 & 4673 & 4390 & 4661 & 4419 & 4522 & 3.5 \\
\hline 4 & 4563 & 4514 & 4551 & 4410 & 4585 & 4482 & 4644 & 4483 & 4571 & 4421 & 4469 & 4309 & 4500 & 2.0 \\
\hline 5 & 4636 & 4636 & 4627 & 4667 & 4522 & 4486 & 4552 & 4541 & 4676 & 4526 & 4419 & 4393 & 4557 & 2.1 \\
\hline 6 & 4638 & 4598 & 4596 & 4612 & $4583^{\circ}$ & 4633 & 4501 & 4473 & 4724 & 4547 & 4594 & 4518 & 4585 & 1.5 \\
\hline 7 & 4699 & 4563 & 4549 & $4 \overline{591}$ & 4566 & 4568 & 4479 & 4465 & 4643 & 4550 & 4599 & 4550 & $\overline{4569}$ & $1 . \overline{4}$ \\
\hline
\end{tabular}

Table 7-Standard error in indirect UPV measured using different number of measurement points

\begin{tabular}{|c|c|c|c|c|c|c|c|c|c|c|c|c|c|}
\hline \multirow{4}{*}{$\begin{array}{c}\text { Number of } \\
\text { measurement points }\end{array}$} & \multicolumn{6}{|c|}{$\mathrm{PCl}$} & \multicolumn{6}{|c|}{$\mathrm{PC} 2$} & \multirow[b]{4}{*}{ Mean, $\mathrm{m} / \mathrm{s}$} \\
\hline & \multicolumn{12}{|c|}{ Pulser transducer location } & \\
\hline & A20 & $\mathrm{B} 20$ & $\overline{\mathrm{C} 20}$ & A40 & $\mathrm{B} 40$ & $\mathrm{C} 40$ & A20 & $\mathrm{B} 20$ & $\mathrm{C} 20$ & A40 & B40 & $\mathrm{C} 40$ & \\
\hline & \multicolumn{12}{|c|}{ Indirect UPV standard error, $\mathrm{m} / \mathrm{s}$} & \\
\hline 2 & - & - & - & - & - & - & - & - & $-\cdots$ & - & - & - & - \\
\hline 3 & 48 & 71 & 43 & 323 & 117 & 276 & 11 & 70 & 115 & 431 & 108 & 86 & 141 \\
\hline 4 & 115 & 38 & 61 & 210 & 58 & 126 & 9 & 132 & 78 & 197 & 116 & 73 & 101 \\
\hline 5 & 79 & 77 & 57 & 208 & 48 & 72 & 50 & 84 & 78 & 131 & 71 & 66 & 85 \\
\hline 6 & 52 & 54 & 41 & 138 & 49 & 104 & 44 & 66 & 59 & 87 & 123 & 89 & 76 \\
\hline 7 & 53 & 43 & 39 & 98 & 36 & 82 & 33 & 47 & 61 & 62 & 87 & 67 & 59 \\
\hline
\end{tabular}

Table 8-Standard error of indirect UPV measured using different number of measurement points

\begin{tabular}{c|c|c|c}
\hline $\begin{array}{c}\text { Number of measurement } \\
\text { points }\end{array}$ & $\begin{array}{c}\text { Indirect UPV, } \\
\mathrm{m} / \mathrm{s}\end{array}$ & $\begin{array}{c}\text { Standard error, } \\
\mathrm{m} / \mathrm{s}\end{array}$ & $\begin{array}{c}\text { Percent error, } \\
\%\end{array}$ \\
\hline 2 & 4771 & - & - \\
\hline 3 & 4522 & 141 & 3.13 \\
\hline 4 & 4500 & 101 & 2.25 \\
\hline 5 & 4557 & 85 & 1.87 \\
\hline 6 & 4585 & 76 & 1.65 \\
\hline 7 & 4569 & 59 & 1.29 \\
\hline
\end{tabular}

the maximum coarse aggregate size and gradation, can influence this variability. Based on these arguments, time-of-flight measurements for spacings of 100 and $148 \mathrm{~mm}$ were not considered.

The indirect UPV computed with increasing number of measurement points is presented in Table 6 . This table is used for determining the minimum required measurement points. The standard error for the indirect UPV determination of each transducer arrangement is presented in Table 7.
As the number of measurement points is increased from two to seven, variability (COV) of indirect UPV decreased from 4.8 to $1.4 \%$, and the mean standard error for each determination decreased from 141 to $59 \mathrm{~m} / \mathrm{s}$. The minimum number of measurement points is established by assuming a maximum acceptable UPV variability of $2.0 \%$. In determining the maximum acceptable variability, all previous measurements of direct and indirect UPVs were reviewed and a specimenrelated variability of $2.0 \%$ was observed. Those seeking d lower value of variability in UPV measurement can achieve this by increasing the number of receiving transducer locations A maximum of $2.0 \%$ variability in UPV was reached using a minimum of four receiving transducer locations. Table 8, on the other hand, presents the percent error in UPV corresponding to the increasing number of transducer locations also showing decreasing error with increasing measurement locations. Again, using four transducers results in a UPV measurement error of close to $2.0 \%$.

As a recommendation, indirect UPV measurement may use a minimum of four measurements along an axis with 
transducers placed evenly at 200 to $350 \mathrm{~mm}$ separations. This recommendation is limited to ultrasonic wave transmission at frequencies around $50 \mathrm{kHz}$ corresponding to a wavelength of approximately $90 \mathrm{~mm}$.

\section{SUMMARY AND CONCLUSIONS}

This study was conducted to develop a procedure for measuring the indirect LPVs in concrete slabs and for appraising the similarity between direct and indirect UPVs. Ultrasonic pulse velocities were measured using direct and indirect arrangements on two plain concrete slab specimens.

Two approaches were used for indirect measurements. In the first approach, indirect UPV was computed as the ratio of wave path length between the transmitting and receiving transducer to the time of Might. Using different definitions for wave path length, such as center-to-center or edge-toedge of the transducers, resulted in large differences in indirect UPV. In the second approach, measurements were made along a line on the surface of the concrete specimen with increasing separation between transmitting and receiving transducers. UPV was determined with significantly lower variability from the inverse of the slope of the linear relationship between transducer separation and time of flight. Further analysis of the results indicated that a minimum of four measurement points is needed on the transducer separationtime of flight plot to obtain a wave speed variability of $2.0 \%$. It is recommended that the first measurement is made at approximately two wavelengths from the transmitting transducer and the transducer separation is increased for consecutive measurements with approximately $50 \mathrm{~mm}$ intervals (half wavelength). The average indirect UPV was determined to be $4500 \mathrm{~m} / \mathrm{s}$ when computed using four measurements performed with transducer spacings of 200 to $350 \mathrm{~mm}$. The corresponding average standard error was about $100 \mathrm{~m} / \mathrm{s}$.

The most significant conclusion is that the indirect UPV is statistically similar to direct UPV measured on the concrete slab specimens provided that there are uniform properties, including moisture gradient along the surface and along the depth.

\section{ACKNOWLEDGMENTS}

This study is funded in part by the Michigan Department of Transportation (MDOT) under a contract titled "Evaluation of Concrete Permeability by Ultrasonic Testing Technıques." The findings and the evaluations expressed in this article are those of the authors and do not necessarily reflect the views of MDOT

\section{REFERENCES}

Ang. A. H.S, and Tang, W H., 1975. Probabliti Concepts in Engineering Planning and Design. V.I. John Wley and Sons. New York, 409 pp.

ASTM C 597. 1999a. "Standard Test Method tor Pulse Velocity through Concrete." Anmual Book of ASTM Stundards. ASTM. West Conshohocken. Pa.

ASTM D 2845, 1999b. "Standard Test Method tor Laboratory Determination of Pulse Velocities and Ultrasontc Elastic Constants of Rock." ASTM D 2845. Annual Book of ASTM Standards, ASTM. West Consho. hocken. Pa.

Benedetu. A.. 1998, "On the U/trasonic Pulse Propagation into Fire Damaged Concrete." ACI Structural Journal. V 95. No. 3. Mav-June. pp. 259-271

BS 1881. 1997. "Recommendations tor Measurement of Pulse Velociry through Concrete." Britush Standards Institute. Part 203. London

Jones. R . 1962. Non-Destrurtue Testing of Concrete. Cambridge Unıversity Press. London. 103 pp.

Krautkramer, J, and Krautkramer. H. 1990. Ultrasonu Testing of Materials, Springer Verlag. New Yorh. $647 \mathrm{pp}$.

Malhotra. V M.. and Canno. N J, 1991. CRC Handbook on Nonde. structive Texting of Concrete. CRC Press. Boca Raton. Fla.. 343 pp.

Popovics. J S.. Song. W. Achenbach. J D. Lee. J H.. and Andre. R F 1998. "One-Sided Stress Wave Velocity Measurement in Concrete," Jour. nal of Engineering Mechumu's. V 124. No. 12. Dec., 1998. pp 1346- 1353

Quixara, L. and Bungey, J H., 1996. "Using Compression Wave Ultraconic Transducers to Measure the Velocity of Surtace Waves and hence Determine Dynamic Modulus of Elasticity for Concrete." Construction and Building Malerials. V 10. No.4. pp. 237.242.

Ravindrarajah. R S.. 1992. "Evaluation of Compressive Strength for High-Strength Concrete by Pulse Velocity Method," Proceedings of the Nondestructive Testing of Concrete Elements and Structures, American Society of Civil Engineers, San Antonio, Tex., pp. 115-126.

Richart, F E., Hall, J R., and Woods, R. D., 1970, Vibrations of Soils and Foundations, Prentice-Hall, Inc., N.J., 414 pp.

RILEM, 1972, Testing of Concrete by Ultrasonic Pulse Method, NDT-1, (after Jones, R., and Facaoaru, I., 1969, "Recommendations for Testing Concrete by the Ultrasonic Pulse Method," Materials and Siructures, V 2 , No. 10, pp. 275-284).

Sansalone, M., Lin, J., and Streett, W B., 1997, "A Procedure for Determining P-Wave Speed in Concrete for Use in Impact-Echo Testing Using a P-wave Speed Measurement Technique," ACl Materials Joumal, V 94 No. 6, Nov.-Dec., pp. 531-539

Swamy, R. N., and Al-Hamed, A. H., 1982, "The Use of Pulse Velocity Measurements to Estimate Strength of Air-Dried Cubes and Hence InSitu Strength of Concrete," In-Situ/NDT Testing of Concrete, SP-82, V M. Malhotra, ed., American Concrete Institute, Farmington Hills, Mich. pp. 201-227

Tomsett, H. N., 1980, "The Practical Use of Ultrasonic Pulse Velocity Measurements in the Assessment of Concrete Quality," Magazine of Concrete Research, V 32, No. 110, pp. 7-15.

Udegbunam, O., Yaman, I. O., Aktan, H., and Hohm, T., 1999, "'Developing a Rapid Measure of Concrete Permeability for Use in QA/QC Specifications," Proceedings of the Transportation Research Board, Paper No. 990565, Washington, D.C

Yaman, 1. O., Udegbunam, O., and Aktan, H., 2000, "Assessing Concrete Permeability from Ultrasonic Pulse Velocity Measurements," Proceedings of the Transportation Research Board. Paper No. 001190. Washington, D.C. 